\title{
Pyrylium salts with 2-(azulen-1-yl) vinyl substituents in 2-, 4- and/or 6-positions
}

\author{
Alexandru C. Razus, ${ }^{\mathrm{a}, *}$ Liliana Cristian, ${ }^{\mathrm{a}}$ Simona Nica, ${ }^{\mathrm{a}, \mathrm{b}}$ Oana Zaharia, ${ }^{\mathrm{a}}$ \\ and Anamaria Hanganu ${ }^{c}$ \\ anstitute of Organic Chemistry "C.D. Nenitzescu" of Romanian Academy, Splaiul Independenţei \\ 202 B, PO Box 35-108, 060023 Bucharest, Romania \\ ${ }^{b}$ Institute of Macromolecular Chemistry "Petru Poni", Grigore-Ghica Voda Alley 41A, 700847 \\ Iasi, Romania \\ "University „Politehnica” of Bucharest, Faculty of Applied Chemistry and Materials Science, \\ "C. D. Nenitzescu" Organic Chemistry Department, 1-7 Gheorghe Polizu, \\ 011061 Bucharest, Romania \\ E-mail: acrazus@cco.ro
}

\begin{abstract}
The synthesis of pyrylium perchlorates substituted with one or more azulen-1-ylvinyl groups was performed using conventional coupling conditions and microwave-assisted protocol. The microwave-assisted synthesis protocol is characterized by shorter reaction times, higher product selectivity and enhanced yields. High bathochromic effect was observed in the electronic spectra by substitution of the heterocycle with azulen-1-ylvinyl groups. The ${ }^{1} \mathrm{H}-\mathrm{NMR}$ spectra confirmed the push-pull property of the products.
\end{abstract}

Keywords: Azulen-1-ylvinyl pyrylium salts, azulen-1-carbaldehydes, microwave-assisted condensation

\section{Introduction}

The azulen-1-yl moiety is known as a very efficient electron-donor group due to the stabilization of the positive charge via generation of the tropylium ion. The coupling of this fragment with an electron acceptor group affords a push-pull system interesting from theoretical as well as from technical (e.g. as NLO material) ${ }^{1}$ point of view. The same property of the azulen-1-yl moiety confers stability of the positively charged organic systems, like pyrylium salts. In our previous papers there were investigated the synthesis and the physical and chemical properties of 2- or 4azulen-1-yl substituted heterocyclic salts, for example compounds $\mathbf{1}$ - $\mathbf{4}$ (Scheme 1). ${ }^{2,3,4}$ 
<smiles>CC1C=Cc2cccc(-c3cc(Cc4ccccc4)[o+]c(Cc4ccccc4)c3)c2C=C1</smiles>

1 2,6-dimethyl, $\mathrm{Rn}=\mathrm{H}$

2 2,6-dimethyl, $\mathrm{Rn}=4,6,8-\mathrm{Me}_{3}$

3 2,6-diphenyl<smiles>CC=C1C2=CCC(=C1c1cc(C)cc(C)[o+]1)C=CC=C2</smiles>

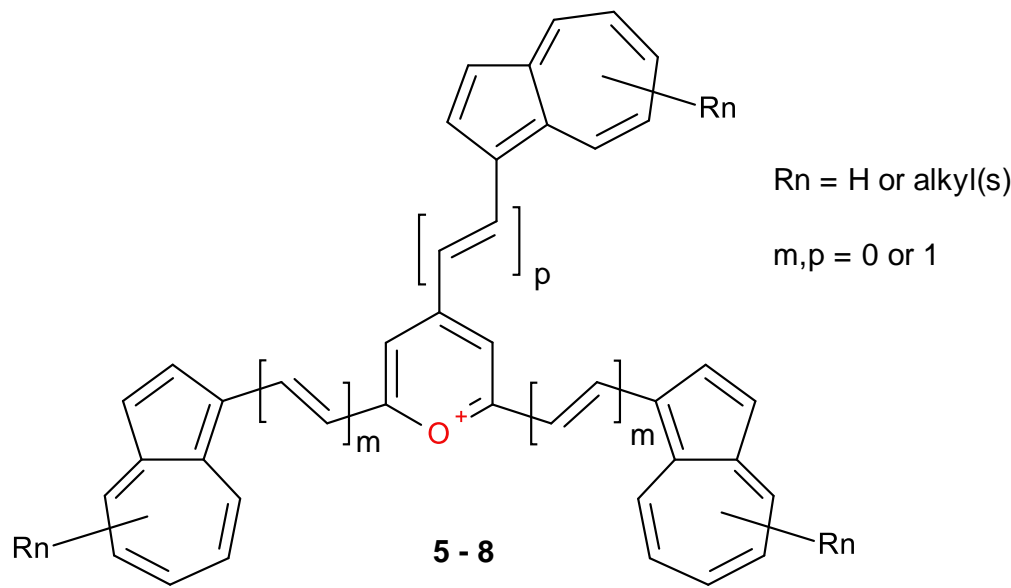

\section{Scheme 1}

The NMR spectra of the studied compounds showed an increased electronic density of the heterocyclic ring simultaneously with the stabilization of the positive charge at the azulen-1-yl moiety as cycloheptatrienylium cation. In order to dissipate more efficiently the positive charge of the heterocycle, we have tried to synthesize 2,4,6-tri(azulen-1-yl)pyrylium salts, compound of type 5, where $\mathrm{m}, \mathrm{p}=0$ applying the reported synthetic protocol for the preparation of the corresponding triphenyl substituted product. ${ }^{5}$ Although, we have isolated the intermediate chalcone, the pyrylium salt could not be separated and characterized, most likely due to its very low solubility. Hence, we focused our attention towards synthesis of compounds in which the central heterocyclic ring is connected to azulen-1-yl moiety by a spacer, for example $\mathrm{C}=\mathrm{C}$ bond, compounds 5 and $\mathbf{6}$ where $\mathrm{p}=0$ and $\mathrm{m}=1$ as well as compounds $\mathbf{7}$ and $\mathbf{8}$ where $\mathrm{p}=\mathrm{m}=1$. We report herein the synthesis and the investigation of several properties of this class of compounds.

\section{Results and Discussion}

\section{Synthesis}

The synthesis of the studied pyrylium salts is based on the condensation of azulen-1carbaldehydes with active methyl groups at C-2, C-4 and C-6 positions of the pyrylium ring. As 
carbonyl compounds azulen-1-carbaldehyde and 4,6,8-trimethylazulen-1-carbaldehyde were used and, as coupling reagents were chosen 4-(azulen-1-yl)-2,6-dimethylpyrylium and 2,4,6trimethylpyrylium perchlorates. The conventional condensation, in refluxing acetic anhydride, occurred with modest yields whereas the microwave-assisted synthesis $\left(200{ }^{\circ} \mathrm{C}, 1 \mathrm{~min}\right)$ significantly increased the yields. Depending on the used reaction conditions, when two or three methyl groups are present in the starting pyrylium salt, the condensation took place step-by-step forming a mixture of mono, di and trivinyl derivatives. However, in the microwave-assisted synthesis only the completely condensed product was formed. This is a significant improvement of the reaction protocol since, following the conventional reaction pathway, repetitive column chromatography was necessary to separate the low-condensation products from the completely condensed ones.

The reaction of 4-(Rn-azulen-1-yl)-2,6-dimethylpyrylium perchlorates, $\mathbf{1}$ and $\mathbf{2},{ }^{2}$ with azulen1-carbaldehydes is shown in Scheme 2 and Table 1. When a short reaction time and a lower temperature were used, the mono-condensation products, $\mathbf{5 m}$ and $\mathbf{6 m}$, were formed in moderate yields along with traces of the corresponding di-condensation compounds $\mathbf{5 d}$ and $\mathbf{6 d}$. The prolonged reaction time and higher temperature have reversed the ratio between mono and dicondensation products. The microwave irradiation produced only the divinyl compounds $\mathbf{5 d}$ or 6d and, at the same time, a spectacular increase of the reaction yields (up to $75 \%$ ) in a very short reaction time was obtained (Table 1).

Table 1. Condensation of 4-(Rn-azulen-1-yl)-2,6-dimethylpyrylium perchlorates with azulen-1carbaldehydes

\begin{tabular}{|c|c|c|c|}
\hline Starting aldehyde & Conditions & \multicolumn{2}{|c|}{ Products/yield (\%) } \\
\hline \multirow[t]{3}{*}{ Azulen-1-carbaldehyde } & $100{ }^{\circ} \mathrm{C} / 10-15 \mathrm{~min}$ & $\mathbf{5 d} /$ traces & $\mathbf{5 m} / 50$ \\
\hline & reflux / $30 \mathrm{~min}$ & $\mathbf{5 d} / 35-40$ & $\mathbf{5 m} / 5-7$ \\
\hline & $\mathrm{MW}^{\mathrm{a}}$ & \multicolumn{2}{|c|}{$\mathbf{5 d} / 85^{\mathrm{b}}$} \\
\hline \multirow[t]{3}{*}{ 4,6,8-Trimethyl-azulen-1-carbaldehyde } & $100^{\circ} \mathrm{C} / 10-15 \mathrm{~min}$ & $\mathbf{6 d} /$ traces & $6 \mathbf{m} / 47$ \\
\hline & reflux / $30 \mathrm{~min}$ & $\mathbf{6 d} / 45-50$ & $6 \mathbf{m} / 5-10$ \\
\hline & $\mathrm{MW}^{\mathrm{a}}$ & \multicolumn{2}{|c|}{$\mathbf{6 d} / 78^{\mathrm{b}}$} \\
\hline
\end{tabular}

${ }^{\mathrm{a}}$ Microwave irradiation at $200{ }^{\circ} \mathrm{C}$ for $1 \mathrm{~min}$. ${ }^{\mathrm{b}}$ Traces of $\mathbf{5 m}$ or $\mathbf{6 m}$ were detected. 


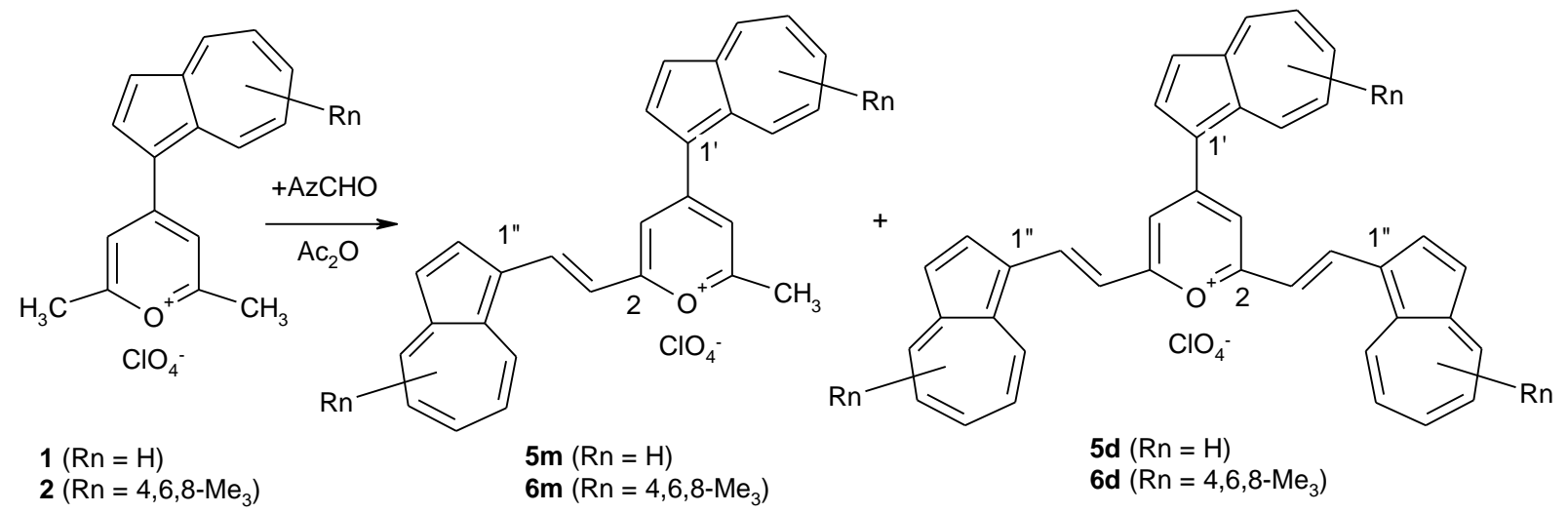

\section{Scheme 2}

The above mentioned synthetic routes were also used for the condensation of 2,4,6trimethylpyrylium perchlorate with azulen-1-carbaldehydes, Scheme 3 and Table 2. Using the conventional procedure, at $100{ }^{\circ} \mathrm{C}$ only the methyl group at $\mathrm{C}-4$ position reacted and the yield in the corresponding monovinyl compounds, $\mathbf{7 m}$ and $\mathbf{8 m}$, was up to $90 \%$. At $160{ }^{\circ} \mathrm{C}$ the reaction afforded trivinyl compounds $\mathbf{7 t}$ and $\mathbf{8 t}$ as major product together with small amounts of divinyl derivatives $\mathbf{7 d}$ and $\mathbf{8 d}$. It is interesting to note that, no increase in the yield was observed under microwave irradiation despite the success registered in the above reported condensation of compounds 1 and 2. However, the MW condensation of 2,4,6-trimethylpyrylium salt generated only the trivinyl compounds $\mathbf{7 t}$ and $\mathbf{8 t}$ and thus favored the separation and the characterization of these products. The short reaction time was another advantage of this last synthetic route.

Table 2. Condensation reaction of 2,4,6-trimethylpyrylium perchlorate with azulen-1carbaldehydes

\begin{tabular}{ccc}
\hline Starting aldehyde & Conditions & Products/yield (\%) \\
\hline Azulen-1-carbaldehyde & $100^{\circ} \mathrm{C} / 10-15 \mathrm{~min}$ & $\mathbf{7 m} / 90-95$ \\
& $160^{\circ} \mathrm{C} / 30 \mathrm{~min}$ & $\mathbf{7 d} / 50-60 \quad \mathbf{7 t} / 15-20$ \\
4,6,8-Trimethyl-azulen-1-carbaldehyde & $100^{\circ} \mathrm{C} / 10-15 \mathrm{~min}$ & $\mathbf{7 t} / 50^{\mathrm{b}}$ \\
& $160^{\circ} \mathrm{C} / 30 \mathrm{~min}$ & $\mathbf{8 d} / 50-60 \quad \mathbf{8 t} / 15-20$ \\
& $\mathrm{MW}^{\mathrm{a}}$ & $\mathbf{8 t} / 55^{\mathrm{b}}$ \\
\hline
\end{tabular}

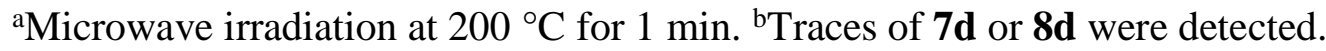



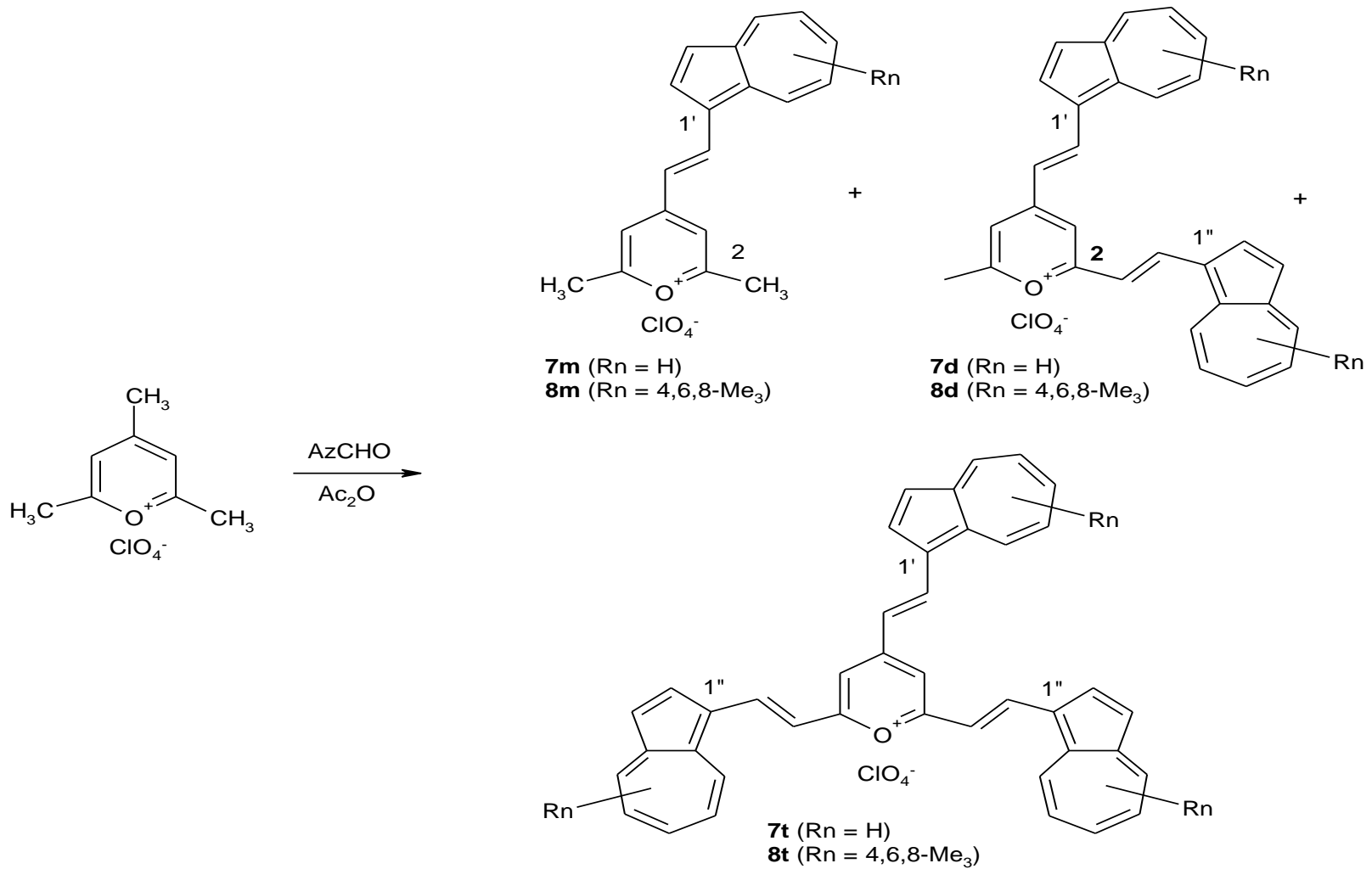

\section{Scheme 3}

\section{Electronic spectra}

Recording of the UV-Vis spectra of the obtained pyrylium perchlorates encountered high difficulties due to their very low solubility in all used organic solvents even under ultra-sound irradiation. Nevertheless, several considerations on the influence of the compounds structure on the $\lambda_{\max }$ of main visible band can be made. As can be seen in Table 3, replacement of one methyl in compound $\mathbf{1}$ by azulen-1-ylvinyl group produces a high bathochromic effect in $\mathbf{5 m}$. This effect increases by introduction of the second azulen-1-ylvinyl moiety, compound $\mathbf{5 d}$. The $\lambda_{\max }$ for $4-$ (azulen-1-ylvinyl)-2,6-dimethylpyrylium salt, $\mathbf{7 m}$, was bathochromically shifted as compared with the corresponding 4-(azulen-1-yl) substituted compound, $\mathbf{1}$. This effect is entirely consistent with the steric interference appeared between azulenyl moiety and the pyrylium ring. In compound $\mathbf{1}$, the coplanarity between the two moieties is hindered ${ }^{2}$ decreasing their conjugation as compared with compound $\mathbf{7 m}$. At the same time, the presence of the double bond $\mathrm{C}=\mathrm{C}$ in compound $7 \mathbf{m}$ contributes to the extension of the $\pi$-electronic system. As expected, a second and even a third azulen-1-ylvinyl moiety present at C-2 and C-6 positions induced a higher bathochromic shift of the visible absorption maximum, in order: $\mathbf{7 m}>\mathbf{7 d}>\mathbf{7 t}$. In the case of tris(4,6,8-trimethylazulen-1-ylvinyl) substituted heterocycles a higher bathochromic shift is produced (see Experimental Part) due to the stabilizing inductive effect of the alkyl groups upon the tropylium cation. 
Table 3. Absorption maxima $\lambda_{\max }(\mathrm{nm})$ for main visible band of the pyrylium salts (in acetone).

\begin{tabular}{ccccccc}
\hline Compd. & $\mathbf{1}$ & $\mathbf{5 m}$ & $\mathbf{5 d}$ & $\mathbf{7 m}$ & $\mathbf{7 d}$ & $\mathbf{7 t}$ \\
\hline$\lambda(\log \varepsilon)$ & $471(4.18)$ & $575(3.25)$ & $601(5.08)$ & $576(4.41)$ & $691(5.03)$ & $690(4.94)$ \\
\hline
\end{tabular}

\section{${ }^{1}$ H-NMR spectra}

The low solubility of the pyrylium perchlorates also rends difficult the recording of ${ }^{13} \mathrm{C}-\mathrm{NMR}$ spectra and HETCOR experiments. Therefore, only the ${ }^{1} \mathrm{H}-\mathrm{NMR}$ spectra of the compounds were recorded and will be discussed in the present paper.

Heterocycle protons (3- and 5-H). The comparison between the $\delta$ of protons at C-3(5) in pyrylium ring of 4,6,8-triphenylpyrylium salt $(9.17 \mathrm{ppm})$ and the same protons in compound 3 $(8.06 \mathrm{ppm})^{2}$ shows the increase in electron density at pyrylium moiety by conjugation between azulenyl moiety and positively charged heterocycle. In compound $\mathbf{3}$, this influence is in a certain extent diminished by the closer proximity of the azulenyl magnetic field.

The magnetic field of the azulenyl group in compound $\mathbf{7 m}$ is far from the protons at C-3(5) and the influence of the magnetic field of $\mathrm{C}=\mathrm{C}$ double bond is weak. In this compound only the conjugation between azulenyl and pyrylium moieties through the spacer $\mathrm{C}=\mathrm{C}$ takes place and produces a pronounced shielding of the protons at C-3(5) (Table 4) as compared to compound 1 ( $\Delta \delta \approx 0.2 \mathrm{ppm}$ ). This effect is emphasized by the inductive effect of the three methyl groups in compound $\mathbf{8 m}$ ( $\Delta \delta$ between compounds $\mathbf{7 m}$ and $\mathbf{8 m} \approx 0.25 \mathrm{ppm}$ ). The two azulen-1-ylvinyl moieties located at C-2 and C-6 positions in compound 7t influenced only in a small extent the protons 3-H and 5-H of the pyrylium ring.

Ethylene protons. As results from Table 4, the value of $\delta$ for az- $\underline{C} \underline{H}=$ is always higher than that for py-C $\underline{H}=$ and this difference is higher for the ethylene at C-4 than at C-2(6). There are two reasonable explanations for this behavior and the most important is the charge distribution over the 1-(azulen-1-yl)-2-(4(2)-pyrylium)ethylene system as is represented in Scheme 4. Thus, for $\mathbf{7 m}$ there are three resonance structures which contribute essentially to the real molecular charge distribution, the pyrylium, Py, the quasi-quinolinic, $\mathbf{Q}$, and the tropylium, $\mathbf{T}$, structures. Despite the lower contribution of the structure $\mathbf{Q}$, the positive charge at the carbon atom in the az- $\underline{\mathrm{H}}=$ fragment is increased. Indeed, using MOPAC package and PM3 approach, the calculated net atomic charge for the carbon atom placed near the azulene is +0.1123 whereas, for the carbon bounded on pyrylium ring is -0.2867 . Therefore, the lower electron density at the first proton produces a bathochromic shift. 


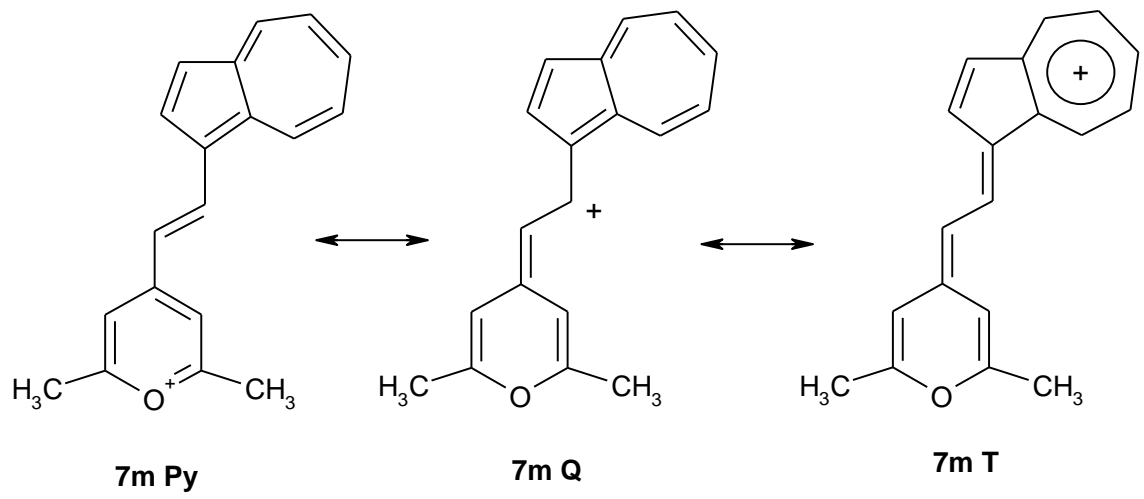

\section{Scheme 4}

These arguments seem to be confirmed by the fact that when, the azulenyl moiety is substituted with methyl groups as in $\mathbf{8 m}$, the contribution of the structure $\mathbf{T}$ increases and that of the structure $\mathbf{Q}$ decreases. The MOPAC calculations result in +0.1064 and -0.2892 values for the two above discussed carbon atoms. Hence, the difference between the value of $\delta$ for the protons in az-C$\underline{H}=$ and py- $\underline{H}=$ fragments decreases in compound $\mathbf{8 m}$ as compared to the same difference for compound $\mathbf{7 m}$.

The influence exerted by the magnetic fields of the pyrylium or of the azulenyl ring over the ethylene protons could also contribute to the difference between the value of $\delta$ for az- $\underline{C} \underline{H}=$ and py- $\underline{C} \underline{H}=$.

Table 4. Heterocycle and ethylene protons $(\delta, \mathrm{ppm})$

\begin{tabular}{cccccc}
\hline Compound & 3-and 5-H & 2-(py)-CH= & 2-(az)-CH= & 4-(py)-CH= & 4-(az)-CH= ${ }^{\mathrm{a}}$ \\
\hline $\mathbf{1}^{\mathrm{b}}$ & 8.06 & - & - & - & - \\
$\mathbf{7} \mathbf{m}$ & 7.87 & - & - & 7.36 & 9.07 \\
$\mathbf{8 m}$ & 7.61 & - & - & 7.25 & 9.02 \\
$\mathbf{7 t}$ & 7.81 & 7.30 & 8.65 & 7.24 & 8.75 \\
$\mathbf{8 t}$ & 7.23 & 6.92 & 8.22 & 7.03 & 8.32 \\
$\mathbf{5 d}$ & 8.04 & 7.47 & 8.77 & - & - \\
\hline
\end{tabular}

${ }^{\mathrm{a}} \mathrm{py}=$ pyrylium moiety. ${ }^{\mathrm{b}} \mathrm{Rn}=\mathrm{H}$.

Azulenyl protons. We have previously reported that, the substitution of the azulenyl system at C-1 position with positively charged heterocycle (in 2 or 4 position) as in compounds $\mathbf{1}-\mathbf{3}$, strongly deshielded the azulenyl protons. ${ }^{2,3}$ The introduction of a $\mathrm{C}=\mathrm{C}$ spacer between azulenyl and pyrylium moieties as in compound $\mathbf{7 m}$ causes only a little increase of the $\delta$ values of the azulenyl protons, as comparing with compound $\mathbf{1}$ (Table 5). 
Table 5. Azulenyl protons $(\delta, \mathrm{ppm})$

\begin{tabular}{cccccccc}
\hline \multirow{2}{*}{ Compound } & \multicolumn{7}{c}{${ }^{1} \mathrm{H}$} \\
\cline { 2 - 8 } Azulene & 2 & 3 & 4 & 5 & 6 & 7 & 8 \\
$\mathbf{1}$ & 7.81 & 7.30 & 8.23 & 7.05 & 7.45 & 7.05 & 8.23 \\
$\mathbf{7 m}$ & 8.45 & 7.51 & 8.65 & 7.77 & 8.07 & 7.80 & 9.12 \\
\hline
\end{tabular}

\section{Conclusions}

The synthesis of pyrylium perchlorates substituted with one or more azulen-1-ylvinyl groups, compounds 5 and $\mathbf{6 m}$ and $\mathbf{6 d}, \mathbf{7}$ and $\mathbf{8 m}, 8 \mathrm{~d}$ and $8 \mathrm{t}$ was performed by condensation of the corresponding methyl substituted salts with azulen-1-carbaldehydes. The microwave-assisted synthetic protocol is characterized by shorter reaction times, enhanced yields and improved product purities with the respect to the use of conventional coupling method. This main achievement allowed a simple workup of the reaction mixture and permitted a facile separation of pure products. The ${ }^{1} \mathrm{H}-\mathrm{NMR}$ spectra confirmed the increase in the electron density at the heterocyclic ring and, at the same time, the contribution of the tropylium structure of the azulenyl moiety. The dissipation of the electron density over the entire molecule is more pronounced as compared to the corresponding system with the azulenyl group direct bounded to the heterocyclic ring as in compounds $\mathbf{1}-\mathbf{3}$. In these last cases, the coplanarity between the two moieties was hindered followed by the decrease in electron conjugation. This fact is reflected in the ${ }^{1} \mathrm{H}-\mathrm{NMR}$ as well as in the electronic spectra of the investigated compounds. The obtained compounds are valuable synthones for the generation of the corresponding pyridines and pyridinium salts. Our attention is focused on the synthesis of other pyrylium and pyridinium salts where the spacer between heterocycle and azulenyl moieties consists in more than one $\mathrm{C}=\mathrm{C}$ double bond. The pyridinium salts with an adequate substituent at the nitrogen atom can possess valuable NLO properties. We are also interested in the investigation of compounds $\mathbf{5}-\mathbf{8}$ with varied functions substituted at azulenyl moieties. These investigations are in progress.

\section{Experimental Section}

General. Melting points: Koehler Automatic Melting Point Range Apparatus (K90190). Elemental analyses: Perkin Elmer CHN 240B. UV-Vis spectra: Varian Cary 100 spectrophotometer. NMR spectra in DMSO-d 6 : Bruker Avance DRX4 $\left({ }^{1} \mathrm{H}: 400 \mathrm{MHz},{ }^{13} \mathrm{C}\right.$ : $100.62 \mathrm{MHz})$ spectrometer; chemical shifts $(\delta)$ are expressed in ppm, and $J$ values are given in Hz. The very low solubility of the studied pyrylium salts caused great difficulties in recording of their UV-Vis and ${ }^{1} \mathrm{H}-\mathrm{NMR}$ spectra and made impossible the ${ }^{13} \mathrm{C}-\mathrm{NMR}$ spectroscopy. Mass spectra were recorded on Varian 1200L Quadrupole/MS/MS spectrometer by direct injection in 
ESI or APCI. Microwave irradiation was carried out using a Biotage Initiator 2.0 EXP - ED instrument. The IR spectra are not relevant for the structure assignment of investigated compounds. For the column chromatography silica gel (70-230 mesh ASTM) was used. Dichloromethane (DCM) was dried over $\mathrm{CaH}_{2}$. Numbering of the atoms in the herein described compounds is given in Schemes 2-4.

Starting reagents. The protocols described in the literature were used for the synthesis of azulen-1-carbaldehyde, ${ }^{6} \quad$ 4,6,8-trimethylazulen-1-carbaldehyde, ${ }^{5} \quad$ 2,4,6-trimethylpyrylium perchlorate, ${ }^{7}$ 4-(azulen-1-yl)-2,6-dimethylpyrylium perchlorate ${ }^{2}$ and 4-(4,6,8-trimethylazulen-1yl)-2,6-dimethylpyrylium perchlorate. ${ }^{2}$

General procedure for the condensation of 4-(Rn-azulen-1-yl)-2,6-dimethylpyrylium perchlorates with azulen-1-carbaldehydes

Conventional condensation. Azulen-1-carbaldehyde (1 mmol) and 4-(Rn-azulen-1-yl)-2,6dimethylpyrylium perchlorate $(0.5 \mathrm{mmol})$ were dissolved in acetic anhydride $(10 \mathrm{~mL})$ and the solution was stirred for $10-15$ minutes at $100{ }^{\circ} \mathrm{C}$, under inert atmosphere. At this time the reaction mixture turned from purple to dark blue and the monovinyl derivative, $\mathbf{5 m}$ or $\mathbf{6 m}$, were formed (Table 1). When these are the desired products the reaction mixture was cooled at room temperature and poured into diethyl ether. The precipitate was filtered off. The product was separated from the unreacted aldehyde and traces of divinyl derivative by column chromatography on silica gel using DCM/acetone as eluting mixture. When the reaction was performed at reflux temperature for 30 minutes, the color of the solution turned to green and the divinyl derivatives $\mathbf{5} \mathbf{d}$ or $\mathbf{6 d}$ were the major products. The reaction mixture was cooled to room temperature and poured into diethyl ether. The solid precipitate containing a mixture of monovinyl and divinyl derivatives was collected by filtration. The two products were separated by column chromatography on silica gel using DCM/acetone $(6 / 1)$ as eluting mixture.

Microwave synthesis. The azulen-1-carbaldehyde (1 mmol) and 4-(Rn-azulene-1-yl)-2,6dimethylpyrylium perchlorate $(0.5 \mathrm{mmol})$ were introduced in a $2-5 \mathrm{~mL}$ reaction vial and acetic anhydride $(5 \mathrm{~mL})$ was subsequently added. The reaction vial was sealed and irradiated for one minute at $200{ }^{\circ} \mathrm{C}$. The reaction mixture was then cooled at room temperature and poured into diethyl ether. The solid precipitate containing a mixture of divinyl derivative and traces of monovinyl compound was worked-up as above. The results for both procedures are reported in Table 1.

General procedure for the condensation of 2,4,6-trimethylpyrylium perchlorates with azulen-1-carbaldehydes

Conventional condensation. Azulen-1-carbaldehyde (1 $\mathrm{mmol})$ and 2,4,6-trimethylpyrylium perchlorate $(0.33$ mmoles $)$ were dissolved in acetic anhydride $(10 \mathrm{~mL})$ and the reaction mixture was stirred at $100{ }^{\circ} \mathrm{C}$, under inert atmosphere. The reaction mixture turned from purple to violet and after 10-15 minutes the mono-condensation product, $\mathbf{7 m}$ or $\mathbf{8 m}$, was obtained in over $90 \%$ yield. The above mentioned work-up of the reaction mixture yielded the mono-condensation 
products. By increasing the temperature to $160{ }^{\circ} \mathrm{C}$, the color of the solution turned green and after 30 minutes a mixture of divinyl and trivinyl products, $\mathbf{7 m}$ or $\mathbf{8 m}$ and $\mathbf{7 t}$ or $\mathbf{8 t}$, was obtained. The reaction mixture was cooled at room temperature and poured into diethyl ether. Purification of the compounds was performed by repetitive column chromatography on silica gel using the above mentioned elution mixture.

Microwave synthesis. The azulen-1-carbaldehyde $(1 \mathrm{mmol})$ and 2,4,6-trimethylpyrylium perchlorate $(0.33$ mmoles $)$ were introduced in a $2-5 \mathrm{~mL}$ reaction vial and acetic anhydride $(5$ $\mathrm{mL}$ ) was added. The reaction vial was sealed and irradiated for one minute at $200{ }^{\circ} \mathrm{C}$. The reaction mixture was then cooled to room temperature and poured into diethyl ether. The solid precipitate containing the tris(azulen-1-ylvinyl)pyrylium salt $\mathbf{7 m}$ or $\mathbf{8 m}$, along with traces of biscondensation product (the mono-condensation product was not detected in the reaction mixture) was separated by column chromatography on silica gel using DCM/acetone (6/1) as eluting solvents. The results for both procedures are reported in Table 2.

4-Azulen-1-yl-2-[(E)-2-azulen-1-ylvinyl]-6-methylpyrylium perchlorate (5m). Dark blue powder, mp 132 - $134{ }^{\circ} \mathrm{C}$; UV-Vis (acetone): $\lambda_{\max }(\log \varepsilon): 602$ (sh), 575 (3.25), 558 (3.23), nm; ${ }^{1} \mathrm{H}$ NMR (DMSO-d $): \delta 2.76(\mathrm{~s}, 6 \mathrm{H}, 2,6-\mathrm{Me}), 7.39$ (d, 1H, J = $\left.15.2 \mathrm{~Hz},(\mathrm{py})-\mathrm{CH}=\right), 7.52(\mathrm{t}, J=$ $\left.9.8 \mathrm{~Hz}, 1 \mathrm{H}, 5^{\prime \prime}-\mathrm{H}\right), 7.58$ (t, $\left.J=9.8 \mathrm{~Hz}, 1 \mathrm{H}, 7^{\prime \prime}-\mathrm{H}\right), 7.61\left(\mathrm{~d}, J=4.0 \mathrm{~Hz}, 1 \mathrm{H}, 3^{\prime \prime}-\mathrm{H}\right), 7.67$ (d, $J=$ $\left.4.4 \mathrm{~Hz}, 1 \mathrm{H}, 3^{\prime}-\mathrm{H}\right), 7.81\left(\mathrm{t}, J=9.6 \mathrm{~Hz}, 1 \mathrm{H}, 5^{\prime}-\mathrm{H}\right), 7.88$ (t, $\left.J=9.8 \mathrm{~Hz}, 1 \mathrm{H}, 7^{\prime}-\mathrm{H}\right), 7.91$ (s, 1H, 5-H), $7.93\left(\mathrm{t}, J=9.8 \mathrm{~Hz}, 1 \mathrm{H}, 6^{\prime \prime}-\mathrm{H}\right), 8.15$ (t, $\left.J=9.8 \mathrm{~Hz}, 1 \mathrm{H}, 6^{\prime}-\mathrm{H}\right), 8.22(\mathrm{~s}, 1 \mathrm{H}, 3-\mathrm{H}), 8.45$ (d, $J=4.4$ $\left.\mathrm{Hz}, 1 \mathrm{H}, 2^{\prime \prime}-\mathrm{H}\right), 8.53$ (d, $\left.J=9.6 \mathrm{~Hz}, 1 \mathrm{H}, 4^{\prime \prime}-\mathrm{H}\right), 8.56$ (d, $\left.J=4.4 \mathrm{~Hz}, 1 \mathrm{H}, 2^{\prime}-\mathrm{H}\right), 8.66$ (d, $J=15.6$ $\mathrm{Hz}, 1 \mathrm{H},(\mathrm{az})-\mathrm{CH}=), 8.74$ (d, $\left.J=9.6 \mathrm{~Hz}, 1 \mathrm{H}, 4^{\prime}-\mathrm{H}\right), 9.01$ (d, $\left.J=10.0 \mathrm{~Hz}, 1 \mathrm{H}, 8^{\prime \prime}-\mathrm{H}\right), 9.19$ (d, $J=$ $\left.10.0 \mathrm{~Hz}, 1 \mathrm{H}, 8^{\prime}-\mathrm{H}\right)$ ppm; ESI-MS: $m / z(\%)=373.0(100)\left[\mathrm{M}^{+}+1\right], 511$ (70), 553 (10). Anal. Calcd for $\mathrm{C}_{28} \mathrm{H}_{21} \mathrm{ClO}_{5}$ : C, 71.11; H, 4.48; Cl, 7.50. Found: C, 71.15; H, 4.45; Cl, 7.57.

4-Azulen-1-yl-2,6-bis[(E)-2-azulen-1-ylvinyl]pyrylium perchlorate (5d). Dark green powder, mp 195 - $197{ }^{\circ} \mathrm{C}$; UV-Vis (acetone): $\lambda_{\max }(\log \varepsilon): 685$ (sh), 601 (5.08), 478 (4.53), 429 (4.73) nm; ${ }^{1} \mathrm{H}$ NMR (DMSO-d $): \delta 7.47$ (d, $\left.J=15.2 \mathrm{~Hz}, 2 \mathrm{H},(\mathrm{py})-\mathrm{CH}=\right), 7.53\left(\mathrm{t}, J=9.6 \mathrm{~Hz}, 2 \mathrm{H}, 5^{\prime \prime}-\mathrm{H}\right), 7.59$ (t, $\left.J=10.0 \mathrm{~Hz}, 2 \mathrm{H}, 7^{\prime \prime}-\mathrm{H}\right), 7.6\left(\mathrm{~d}, J=4.8 \mathrm{~Hz}, 2 \mathrm{H}, 3^{\prime \prime}-\mathrm{H}\right), 7.66$ (d, $\left.J=4.4 \mathrm{~Hz}, 1 \mathrm{H}, 3^{\prime}-\mathrm{H}\right), 7.76$ (t, $J$ $\left.=9.6 \mathrm{~Hz}, 1 \mathrm{H}, 5^{\prime}-\mathrm{H}\right), 7.82\left(\mathrm{t}, J=10.0 \mathrm{~Hz}, 1 \mathrm{H}, 7^{\prime}-\mathrm{H}\right), 7.95\left(\mathrm{t}, J=10.0 \mathrm{~Hz}, 2 \mathrm{H}, 6^{\prime \prime}-\mathrm{H}\right), 8.04(\mathrm{~s}, 2 \mathrm{H}$, 3-H, 5-H), 8.12 (t, $\left.J=10.0 \mathrm{~Hz}, 1 \mathrm{H}, 6^{\prime}-\mathrm{H}\right), 8.47$ (d, $\left.J=4.0 \mathrm{~Hz}, 2 \mathrm{H}, 2^{\prime \prime}-\mathrm{H}\right), 8.54$ (d, $J=9.6 \mathrm{~Hz}$, $\left.2 \mathrm{H}, 4^{\prime \prime}-\mathrm{H}\right), 8.57$ (d, $\left.J=4.4 \mathrm{~Hz}, 1 \mathrm{H}, 2^{\prime}-\mathrm{H}\right), 8.72$ (d, $\left.J=9.6 \mathrm{~Hz}, 1 \mathrm{H}, 4^{\prime}-\mathrm{H}\right), 8.77$ (d, $J=15.6 \mathrm{~Hz}$, 2H, (az)-CH=), 9.10 (d, $\left.J=9.6 \mathrm{~Hz}, 2 \mathrm{H}, 8^{\prime \prime}-\mathrm{H}\right), 9.16$ (d, $\left.J=9.6 \mathrm{~Hz}, 1 \mathrm{H}, 8^{\prime}-\mathrm{H}\right) \mathrm{ppm}$; ESI-MS: $m / z$ $(\%)=511(100)\left[\mathrm{M}^{+}\right]$. Anal. Calcd. for $\mathrm{C}_{39} \mathrm{H}_{27} \mathrm{ClO}_{5}: \mathrm{C}, 76.65 ; \mathrm{H}, 4.45 ; \mathrm{Cl}, 5.80$. Found: $\mathrm{C}$, $76.61 ; \mathrm{H}, 4.43 ; \mathrm{Cl}, 5.75$.

2-Methyl-4-(4,6,8-trimethylazulen-1-yl)-6-[(E)-2-(4,6,8-trimethylazulen-1-yl)vinyl]pyrylium perchlorate $(6 \mathrm{~m})$. Dark blue powder, mp $225-227{ }^{\circ} \mathrm{C}$; UV-Vis (acetone): $\lambda_{\max }(\log \varepsilon) 651$ (4.72), 494 (4.01) nm; ${ }^{1} \mathrm{H}$ NMR (DMSO-d $): \delta 2.65$ (s, $\left.3 \mathrm{H}, 66^{\prime \prime}-\mathrm{Me}\right), 2.71$ (s, 3H, 6'-Me), 2.73 (s, 3H, 4"-Me), 2.84 (s, 3H, 4'-Me), 2.86 (s, 3H, 2-Me), 2.92 (s, 3H, 8"'-Me), 3.18 (s, 3H, 8'-Me), 7.31 (d, $J=15.0 \mathrm{~Hz}, 1 \mathrm{H}$, (py)-CH=), 7.46 (s, 1H, 5-H), 7.47 (s, 1H, 5-H), 7.48 (d, J = 4.5 Hz, 1H, 3"-H), 7.51 (d, J=4.5 Hz, 1H, 3'-H), 7.54 (s, 1H, 7"'-H), 7.61 (s, 1H, 5"-H), 7.68 (s, 2H, 5'H, 7'-H), 8.12 (d, $\left.J=4.5 \mathrm{~Hz}, 1 \mathrm{H}, 2^{\prime \prime}-\mathrm{H}\right), 8.21$ (d, $\left.J=4.5 \mathrm{~Hz}, 1 \mathrm{H}, 2^{\prime}-\mathrm{H}\right), 8.85$ (d, J = 15.0 Hz, 1H, 
$(\mathrm{az})-\mathrm{CH}=)$ ppm; ESI-MS: $m / z(\%)=457(100)\left[\mathrm{M}^{+}\right]$. Anal. Calcd for $\mathrm{C}_{34} \mathrm{H}_{33} \mathrm{ClO}_{5}: \mathrm{C}, 73.30 ; \mathrm{H}$, 5.97; Cl, 6.36. Found: C, 73.33; H, 6.10; Cl, 6.39.

\section{4-(4,6,8-Trimethylazulen-1-yl)-2,6-bis[(E)-2-(4,6,8-trimethylazulen-1-yl)vinyl $]$ pyrylium}

perchlorate (6d). Dark green powder, mp 285 - $286{ }^{\circ} \mathrm{C}$; UV-Vis (acetone): $\lambda_{\max }(\log \varepsilon) 704$ (4.81), 620 (5.03), 485 (4.36), 440 (4.71) nm; ${ }^{1} \mathrm{H}$ NMR (DMSO-d 6 ): $\delta 2.63$ (s, 6H, 6"-Me), 2.73 (s, 3H, 6'-Me), 2.85 (s, 6H, 4"'-Me), 2.86 (s, 3H, 4'-Me), 2.92 (s, 3H, 8'-Me), 3.21 (s, 6H, 8'-Me), $7.30(\mathrm{~d}, J=15.0 \mathrm{~Hz}, 2 \mathrm{H}$, (py)-CH=), 7.39 (s, 2H, 5"-H), 7.41 (s, 2H, 7"-H), 7.46 (d, J = 4.5 Hz, 1H, 3'-H), 7.47 (s, 2H, 5'-H, 7'-H), 7.48 (d, J = 4.7 Hz, 2H, 3"'-H), 7.61 (s, 2H, 3-H, 5-H), 8.16 $\left(\mathrm{d}, J=4.5 \mathrm{~Hz}, 1 \mathrm{H}, 2^{\prime}-\mathrm{H}\right), 8.19$ (d, $\left.J=4.7 \mathrm{~Hz}, 2 \mathrm{H}, 2^{\prime \prime}-\mathrm{H}\right), 8.74$ (d, $\left.J=15.0 \mathrm{~Hz}, 2 \mathrm{H},(\mathrm{az})-\mathrm{CH}=\right)$ ppm; ESI-MS: $m / z(\%)=637(100)\left[\mathrm{M}^{+}\right]$. Anal. Calcd for $\mathrm{C}_{48} \mathrm{H}_{45} \mathrm{ClO}_{5}: \mathrm{C}, 78.19 ; \mathrm{H}, 6.15 ; \mathrm{Cl}$, 4.81. Found: C, 78.22; H, 6.10; Cl, 4.86.

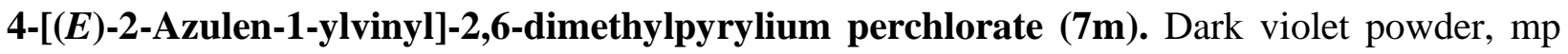
240 - $242{ }^{\circ} \mathrm{C}$; UV-Vis (acetone): $\lambda_{\max }(\log \varepsilon) 605$ (sh), 576 (4.41), 555 (4.39) nm; ${ }^{1} \mathrm{H}$ NMR (DMSO-d 6 ): $\delta 2.66$ (s, 6H, 2-Me, 6-Me), 7.36 (d, J=14.8 Hz, 1H, 4-(py)-CH=), 7.72 (d, $J=4.4$ Hz, 1H, 3'-H), 7.79 (t, $J=9.6$ Hz, 1H, 5'-H), 7.84 (t, $\left.J=9.2 \mathrm{~Hz}, 1 \mathrm{H}, 7^{\prime}-\mathrm{H}\right), 7.87$ (s, 2H, 3-H, 5H), 8.12 (t, $\left.J=10.0 \mathrm{~Hz}, 1 \mathrm{H}, 6^{\prime}-\mathrm{H}\right), 8.57$ (d, $\left.J=4.4 \mathrm{~Hz}, 1 \mathrm{H}, 2^{\prime}-\mathrm{H}\right), 8.71$ (d, $\left.J=9.2 \mathrm{~Hz}, 1 \mathrm{H}, 4^{\prime}-\mathrm{H}\right)$, $9.07(\mathrm{~d}, J=14.8 \mathrm{~Hz}, 1 \mathrm{H}, 4-(\mathrm{az})-\mathrm{CH}=), 9.26\left(\mathrm{~d}, J=10.0 \mathrm{~Hz}, 1 \mathrm{H}, 8^{\prime}-\mathrm{H}\right) \mathrm{ppm}$; ESI-MS: $m / z(\%)=$ $261(100)\left[\mathrm{M}^{+}\right]$. Anal. Calcd for $\mathrm{C}_{19} \mathrm{H}_{17} \mathrm{ClO}_{5}$ : C, 63.25; H, 4.75; Cl, 9.83. Found: C, 63.29; H, 4.70; $\mathrm{Cl}, 9.89$.

2,4-Bis $[(E)$-2-azulen-1-ylvinyl]-6-methylpyrylium perchlorate (7d). Dark blue powder, mp > $350{ }^{\circ} \mathrm{C}$; UV-Vis (acetone): $\lambda_{\max }(\log \varepsilon) 691$ (5.03), 525 (4.24), 432 (3.98) nm; ${ }^{1} \mathrm{H}$ NMR (DMSOd6): $\delta 2.87$ (s, 3H, 2-Me), 7.33 (d, $J=15.2 \mathrm{~Hz}, 1 \mathrm{H}, 2$-(py)-CH=), 7.37 (d, $J=14 \mathrm{~Hz}, 1 \mathrm{H}, 4-$ (py)-CH=), 7.58 (t, $\left.J=9.6 \mathrm{~Hz}, 1 \mathrm{H}, 5^{\prime \prime}-\mathrm{H}\right), 7.62-7.68\left(\mathrm{~m}, 4 \mathrm{H}, 5^{\prime}, 3^{\prime}, 3^{\prime \prime}, 7^{\prime \prime}-\mathrm{H}\right), 7.75$ (t, $J=9.8$ $\left.\mathrm{Hz}, 1 \mathrm{H}, 7^{\prime}-\mathrm{H}\right), 7.83(\mathrm{~s}, 1 \mathrm{H}, 5-\mathrm{H}), 7.87(\mathrm{~s}, 1 \mathrm{H}, 3-\mathrm{H}), 7.97$ (t, $\left.J=10.0 \mathrm{~Hz}, 1 \mathrm{H}, 66^{\prime \prime}-\mathrm{H}\right), 8.05(\mathrm{t}, J=$ $\left.10.0 \mathrm{~Hz}, 1 \mathrm{H}, 6^{\prime}-\mathrm{H}\right), 8.54-8.58$ (m, 2H, 2', 2"'-H), 8.58 (d, J=9.6 Hz, 1H, 4"-H), 8.64 (d, J = 9.6 $\left.\mathrm{Hz}, 1 \mathrm{H}, 4^{\prime}-\mathrm{H}\right), 8.65$ (d, $\left.J=14.8 \mathrm{~Hz}, 1 \mathrm{H}, 2-(\mathrm{az})-\mathrm{CH}=\right), 8.92$ (d, $\left.J=15.2 \mathrm{~Hz}, 1 \mathrm{H}, 4-(\mathrm{az})-\mathrm{CH}=\right)$, $9.05\left(\mathrm{~d}, J=10.4 \mathrm{~Hz}, 1 \mathrm{H}, 8^{\prime \prime}-\mathrm{H}\right), 9.2$ (d, $\left.J=10.0 \mathrm{~Hz}, 1 \mathrm{H}, 8^{\prime}-\mathrm{H}\right) \mathrm{ppm}$; ESI-MS: $m / z(\%)=399(50)$ $\left[\mathrm{M}^{+}\right], 537$ (100). Anal. Calcd for $\mathrm{C}_{30} \mathrm{H}_{23} \mathrm{ClO}_{5}: \mathrm{C}, 72.22 ; \mathrm{H}, 4.65 ; \mathrm{Cl}, 7.11$. Found: C, 72.24; H, $4.63 ; \mathrm{Cl}, 7.18$.

2,4,6-Tris[(E)-2-azulen-1-ylvinyl]pyrylium perchlorate (7t). Dark green powder, mp > 350 ${ }^{\circ} \mathrm{C}$; UV-Vis (acetone): $\lambda_{\max }(\log \varepsilon) 690$ (4.94), 515 (4.21), 433 (4.37) nm; ${ }^{1} \mathrm{H}$ NMR (DMSO-d 6 ): $\delta 7.27$ (d, $J=15.2 \mathrm{~Hz}, 1 \mathrm{H}, 4$-(py)-CH=), 7.30 (d, $J=15.2 \mathrm{~Hz}, 2 \mathrm{H}, 2 / 6-(\mathrm{py})-\mathrm{CH}=)$ ), $7.51(\mathrm{t}, J=$ 9.6 Hz, 2H, 5"-H), 7.54-7.62 (m, 6H, 5', 3', 3", 7"-H), 7.63 (t, J = 9.6 Hz, 1H, 7'-H), 7.81 (s, 2H, 3-H, 5-H), 7.93 (t, $\left.J=9.6 \mathrm{~Hz}, 2 \mathrm{H}, 6^{\prime \prime}-\mathrm{H}\right), 7.95$ (t, $\left.J=9.6 \mathrm{~Hz}, 1 \mathrm{H}, 6^{\prime}-\mathrm{H}\right), 8.44$ (d, $J=4.4 \mathrm{~Hz}, 1 \mathrm{H}$, $\left.2^{\prime}-\mathrm{H}\right), 8.47\left(\mathrm{~d}, J=4.0 \mathrm{~Hz}, 2 \mathrm{H}, 2^{\prime \prime}-\mathrm{H}\right), 8.51\left(\mathrm{~d}, J=9.2 \mathrm{~Hz}, 2 \mathrm{H}, 4^{\prime \prime}-\mathrm{H}\right), 8.53$ (d, $J=8.8 \mathrm{~Hz}, 1 \mathrm{H}, 4^{\prime}-$ $\mathrm{H}), 8.65$ (d, $J=15.6 \mathrm{~Hz}, 2 \mathrm{H}, 2 / 6-(\mathrm{az})-\mathrm{CH}=), 8.75$ (d, $J=15.2 \mathrm{~Hz}, 1 \mathrm{H}, 4-(\mathrm{az})-\mathrm{CH}=), 9.03$ (d, $J=$ $\left.10.4 \mathrm{~Hz}, 2 \mathrm{H}, 8^{\prime \prime}-\mathrm{H}\right), 9.06\left(\mathrm{~d}, J=10.8 \mathrm{~Hz}, 1 \mathrm{H}, 8^{\prime}-\mathrm{H}\right) \mathrm{ppm}$; ESI-MS: $m / z(\%)=537(100)\left[\mathrm{M}^{+}\right]$. Anal. Calcd for $\mathrm{C}_{41} \mathrm{H}_{29} \mathrm{ClO}_{5}: \mathrm{C}, 77.29 ; \mathrm{H}, 4.59 ; \mathrm{Cl}, 5.56$. Found: C, 77.31; H, 4.62; Cl, 5.60.

2,6-Dimethyl-4-[(E)-2-(4,6,8-trimethylazulen-1-yl)vinyl]pyrylium perchlorate (8m). Dark blue powder, $\mathrm{mp}>350{ }^{\circ} \mathrm{C}$; $\mathrm{UV}$-Vis (acetone): $\lambda_{\max }(\log \varepsilon) 599$ (3.52), 573 (3.38), 542 (3.09) nm; 
${ }^{1} \mathrm{H}$ NMR (DMSO-d $): \delta 2.61$ (s, 6H, 2-Me, 6-Me), 2.7 (s, 3H, 6'-Me), 2.9 (s, 3H, 4'-Me), 3.26 (s, $\left.3 \mathrm{H}, 8^{\prime}-\mathrm{Me}\right), 7.25$ (d, $J=14.4 \mathrm{~Hz}, 1 \mathrm{H}, \quad$ (py)-CH=), 7.55 (d, $\left.J=5.2 \mathrm{~Hz}, 1 \mathrm{H}, 3^{\prime}-\mathrm{H}\right), 7.61$ (s, 2H, 3H, 5-H), 7.70 (s, 1H, 5'-H), $7.72\left(\mathrm{~s}, 1 \mathrm{H}, 7^{\prime}-\mathrm{H}\right), 8.35$ (d, $\left.J=4.8 \mathrm{~Hz}, 1 \mathrm{H}, 2^{\prime}-\mathrm{H}\right), 9.02$ (d, $J=14.4$ $\mathrm{Hz}, 1 \mathrm{H},(\mathrm{az})-\mathrm{CH}=)$, ppm; ESI-MS: $m / z(\%)=303(100)\left[\mathrm{M}^{+}\right]$. Anal. Calcd for $\mathrm{C}_{22} \mathrm{H}_{23} \mathrm{ClO}_{5}$ : C, 65.59; H, 5.75; Cl, 8.80. Found: C, 65.62; H, 5.71; Cl, 8.76.

2-Methyl-4,6-bis[(E)-2-(4,6,8-trimethylazulen-1-yl)vinyl]pyrylium perchlorate (8d). Dark blue powder, $\mathrm{mp}>350{ }^{\circ} \mathrm{C}$; UV-Vis (acetone): $\lambda_{\max }(\log \varepsilon) 721$ (4.91), 602 (4.89), 541 (4.53), 448 (3.89) nm; ${ }^{1} \mathrm{H}$ NMR (DMSO-d $): \delta 2.54$ (s, 6H, 6'-H, 6"'-Me), 2.57 (s, 3H, 4'-Me), 2.72 (s, 3H, 4"-Me), 2.91 (s, 3H, 2-Me), 2.92 (s, 3H, 8"-Me), 3.04 (s, 3H, 8'-Me), 7.09 (d, J=14.8 Hz, $1 \mathrm{H}, \quad 4$-(py)-CH=), 7.18 (d, $J=15.2 \mathrm{~Hz}, 1 \mathrm{H}, 2$-(py)-CH=), 7.21-7.42 (m, 6H, 3'-H, 3'-H, 5'-H, 5"-H, 7'-H, 7"-H), 8.16 (d, $\left.J=4.0 \mathrm{~Hz}, 1 \mathrm{H}, 2^{\prime}-\mathrm{H}\right), 8.20$ (d, $\left.J=4.4 \mathrm{~Hz}, 1 \mathrm{H}, 2^{\prime \prime}-\mathrm{H}\right), 8.46$ (d, $J=$ $15.2 \mathrm{~Hz}, 1 \mathrm{H}, 2-(\mathrm{az})-\mathrm{CH}=), 8.64$ (d, $J=14.4 \mathrm{~Hz}, 1 \mathrm{H}, 4-(\mathrm{az})-\mathrm{CH}=)$ ppm; ESI-MS: $m / z(\%)=483$ (100) $\left[\mathrm{M}^{+}\right]$. Anal. Calcd for $\mathrm{C}_{36} \mathrm{H}_{35} \mathrm{ClO}_{5}$ : C, 74.15; H, 6.05; Cl, 6.08. Found: C, 74.12; H, 6.01; $\mathrm{Cl}, 6.14$.

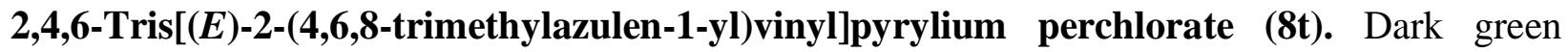
powder, mp > $350{ }^{\circ} \mathrm{C}$; UV-Vis (acetone): $\lambda_{\max }(\log \varepsilon) 734$ (4.82) 539 (3.26), $453(3.51) \mathrm{nm} ;{ }^{1} \mathrm{H}$ NMR (DMSO-d $): \delta 2.50$ (s, 6H, 6"-Me), 2.53 (s, 3H, 6'-Me), 2.67 (s, 6H, 4"-Me), 2.76 (s, 3H, 4'-Me), 2.86 (s, 6H, 8"-Me), 2.92 (s, 3H, 8'-Me), 6.92 (d, J=14.8 Hz, 2H, 2/6(py)-CH=), 7.03 (d, $J=16.0 \mathrm{~Hz}, 1 \mathrm{H}, 4-(\mathrm{py})-\mathrm{CH}=), 7.08\left(\mathrm{~s}, 1 \mathrm{H}, 7^{\prime}-\mathrm{H}\right), 7.13$ (s, 1H, 5'-H), 7.16 (s, 2H, 5'-H), 7.23 (s, 2H, 3, 5-H), 7.20-7.42 (m, 5H, 3'-H, 3"'-H, 7"'-H), 7.94 (d, $\left.J=4.0 \mathrm{~Hz}, 1 \mathrm{H}, 2^{\prime}-\mathrm{H}\right), 8.01$ (d, $J=$ $\left.3.6 \mathrm{~Hz}, 2 \mathrm{H}, 2^{\prime \prime}-\mathrm{H}\right), 8.22$ (d, $\left.J=14.8 \mathrm{~Hz}, 2 \mathrm{H}, 2 / 6-(\mathrm{az})-\mathrm{CH}=\right), 8.32$ (d, $J=14.4 \mathrm{~Hz}, 1 \mathrm{H}, 4-(\mathrm{az})-$ $\mathrm{CH}=)$ ppm; ESI-MS: $\mathrm{m} / z(\%)=663(100)\left[\mathrm{M}^{+}\right]$. Anal. Calcd for $\mathrm{C}_{50} \mathrm{H}_{47} \mathrm{ClO}_{5}$ : C, 78.67; H, 6.21; $\mathrm{Cl}$, 4.64. Found: C, 78.65; H, 6.25; Cl, 4.69.

\section{Acknowledgements}

A. C. Razus thanks to Prof. Klaus Hafner from T. U. Darmstadt for valuable discussions and comments on this work. Simona Nica gratefully acknowledges the financial support of the European Social Fund-,,Cristofor I. Simionescu" Postdoctoral Fellowship Programme (ID POSDRU/89/1.5/S/55216), Sectoral Operational Programme Human Resources Development 2007-2013.

\section{References}

1. (a) Cristian, L.; Sasaki, I.; Lacroix, P. G.; Donnadieu, B.; Asselberghs, I.; Clays, K.; Razus, A. C. Chem. Mater. 2004, 16, 3543. (b) Lacroix, P. G.; Lafant, I.; Iftime, G.; Razus, A. C.; Nakatani, K.; Delaire, J. A. Chem. Eur. J. 2000, 6, 2599. 
2. (a) Razus, A. C.; Birzan, L.; Pavel, C.; Lehadus, O.; Corbu, A. C.; Enache, C. J. Heterocyclic Chem. 2006, 43, 963. (b) Razus, A. C.; Birzan, L.; Zaharia, O.; Enache, C. J. Heterocyclic Chem. 2008, 45, 1139.

3. (a) Razus, A. C.; Birzan, L.; Pavel, C.; Lehadus, O.; Corbu, A.; Chiraleu, F.; Enache, C. $J$. Heterocyclic Chem. 2007, 44, 245. (b) Razus, A. C.; Birzan, L.; Pavel, C.; Lehadus, O.; Corbu, A.; Chiraleu, F.; Enache, C. J. Heterocyclic Chem. 2007, 44, 251.

4. Razus A. C.; Birzan L.; Corbu A.; Enache C.; Arkivoc 2006, 121.

5. Dimroth, K., Reichardt, Vogel, K. Organic Syntheses 1973, Coll. Vol. 5, p 1135.

6. Hafner, K.; Bernhard, C. Angew. Chem. 1975, 69, 553.

7. Balaban, A. T.; Nenitzescu, C. D. Organic Syntheses 1973, Coll. Vol. 5, p 1106.

\section{Graphical Abstract}

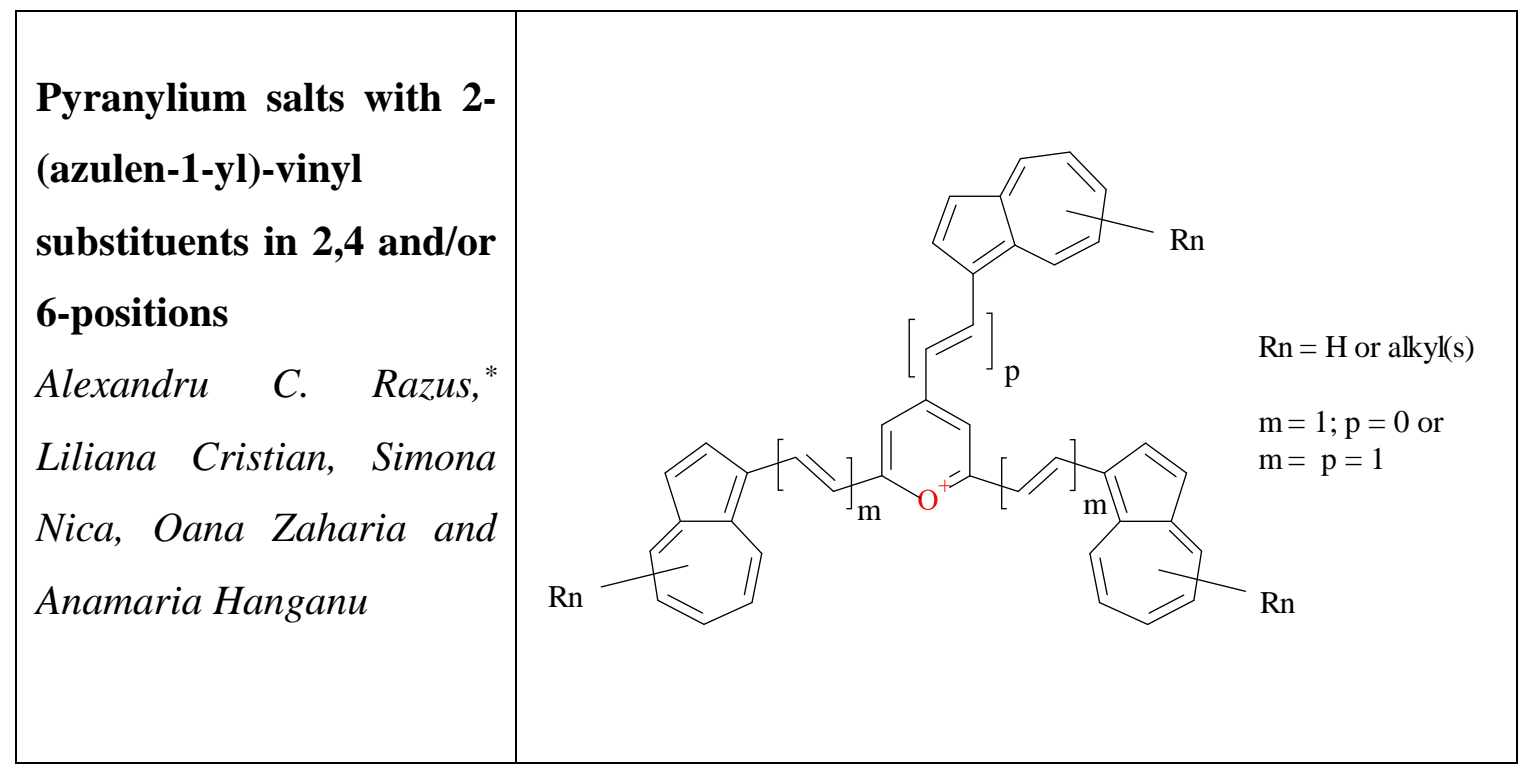

